\title{
КУРЕНИЕ КАК ПРОВОЦИРУЮЩИЙ ФАКТОР РИСКА РАЗВИТИЯ ИШЕМИЧЕСКОГО ИНСУЛЬТА У ЛИЦ С ГЕНЕТИЧЕСКИМ ВАРИАНТОМ RS486055 МАТРИКСНОЙ МЕТАЛЛОПРОТЕИНАЗЫ-10
}

\author{
(С Рымарова Л.В. ${ }^{1}$, Клёсова Е.Ю. ${ }^{2}$, Волкова А.В. ${ }^{1}$, Бушуева О.Ю. ${ }^{1,2}$, \\ Азарова Ю.Э. ${ }^{2,3}$, Ласков В.Б. ${ }^{4}$, Полоников А.В. ${ }^{1,2}$
}

\author{
${ }^{1}$ Кафедра биологии, медицинской генетики и экологии, ${ }^{2}$ научно-исследовательский институт \\ генетической и молекулярной эпидемиологии, ${ }^{3}$ кафедра биологической химии, ${ }^{4}$ кафедра неврологии \\ и нейрохирургии Курского государственного медицинского университета, Курск \\ E-mail: polonikov@rambler.ru
}

\begin{abstract}
Полиморфизм генов матриксных металлопротеиназ вносит значительный вклад в развитие и течение цереброваскулярных заболеваний. Целью настоящего исследования послужил анализ ассоциации полиморфных вариантов генов матриксных металлопротеиназ MMP10 (rs486055) и MMP12 (rs2276109) с риском развития ишемического инсульта (ИИ). Материалом для исследования послужила выборка неродственных индивидов уроженцев Центральной России общей численностью 1073 человека, включая 666 больных ИИ и 407 лиц контрольной группы. Генотипирование полиморфных вариантов генов MMP10 и MMP12 проводилось методом полимеразной цепной реакции в режиме реального времени с дискриминацией аллелей с помощью TaqMan-зондов. Выявлена ассоциация генотипа C/T rs486055 MMP10 с повышенным риском развития ишемического инсульта у курильщиков (OR=1.56 95\% тогда как у некурящих индивидов подобная взаимосвязь генотипа с развитием болезни не наблюдалась. Ассоциации полиморфного варианта rs2276109 гена MMP12 с развитием ИИ не обнаружено. В рамках настоящего исследования впервые выявлена ассоциация генотипа rs486055-C/T MMP10 с повышенным риском развития ишемического инсульта, причем влияние данного генетического варианта на риск развития болезни потенцируется курением.
\end{abstract}

Ключевые слова: ишемический инсульт, генетическая предрасположенность, матриксная металлопротеиназа-10, однонуклеотидный полиморфизм, анализ ассоциации, курение.

\section{SMOKING AS A TRIGGER FACTOR FOR THE DEVELOPMENT OF ISCHEMIC STROKE IN PERSONS WITH THE GENETIC VARIANT OF RS486055 OF MATRIX METALLOPROTEINASE-10}

Rymarova L.V. ${ }^{l}$, Klyosova E.Yu. ${ }^{2}$, Volkova A.V. ${ }^{1}$, Bushueva O.Yu. ${ }^{1,2}$, Azarova Yu.E. ${ }^{2,3}$, Laskov V.B. ${ }^{4}$, Polonikov A.V. ${ }^{1,2}$

${ }^{1}$ Department of Biology, Medical Genetics and Ecology, ${ }^{2}$ Research Institute of Genetic and Molecular Epidemiology, ${ }^{3}$ Department of Biochemistry, ${ }^{4}$ Department of Neurology and Neurosurgery of Kursk State Medical University, Kursk

Polymorphic genes encoding matrix metalloproteinases contribute to the development and outcome of cerebrovascular diseases. The purpose of this study was to analyze the association between polymorphisms of matrix metalloproteinases genes MMP10 (rs486055) and MMP12 (rs2276109) with the risk of ischemic stroke (IS). We examined 1,073 unrelated Russian individuals from Central Russia including 666 IS patients and 407 controls. Genotyping of the MMP10 and MMP12 gene polymorphisms was carried out by TaqMan-based polymerase chain reaction. We found the association of genotype rs486055-C/T of MMP10 with an increased risk of ischemic stroke in smokers (OR $=1.5695 \% \mathrm{CI} 1.02-2.39$, $\mathrm{P}=0.03)$, while non-smoker carriers of the genotype did not possess disease risk. The present study was the first to show the association of genotype rs486055-C/T of the MMP10 gene with an increased risk of ischemic stroke in cigarette smokers.

Keywords: ischemic stroke, genetic predisposition, matrix metalloproteinase-10, single nucleotide polymorphism, association analysis, cigarette smoking.

Сосудистые заболевания головного мозга занимают второе место среди основных причин смертности и инвалидизации населения экономически развитых странах, что определяет данный класс болезней человека как важнейшую медикосоциальную проблему [1]. Значительную долю цереброваскулярных заболеваний занимает ишемический инсульт, формирующийся на фоне атеросклероза мозговых артерий. Согласно современным представлениям ишемический инсульт (ИИ) представляет собой мультифакториальное заболевание, развитие которого обусловлено комплексным взаимодействием генетических и средовых факторов [12]. Многочисленные гене- тические исследования установили широкий спектр генов предрасположенности к ишемическому инсульту $[12,15,27]$.

Известно, что в развитии ишемического инсульта значительная роль отводится дестабилизации атеросклеротических бляшек в церебральных артериях и тромбообразованию [4, 29]. В инициации этих патологических состояний принимают участие матриксные металлопротеиназы - внеклеточные цинк- и кальций-зависимые ферменты эндопептидазы, разрушающие все типы белков внеклеточного матрикса и ремоделирующие соединительную ткань посредством разрушения ее органических компонентов [5, 19]. Идентифици- 
ровано порядка 28 представителей семейства матриксных металлопротеиназ с различными биологическими функциями и субстратной специфичностью [19]. В последнее время в различных странах мира полиморфные варианты генов матриксных металлопротеиназ стали привлекательным объектом генетических исследований этиологии ишемического инсульта $[8,30]$. Однако в российских популяциях до настоящего времени исследований по оценке взаимосвязи полиморфных вариантов генов матриксных металлопротеиназ в развитие ишемического инсульта не проводилось. Целью настоящего исследования послужил анализ ассоциации полиморфных вариантов генов матриксных металлопротеиназ MMP10 (rs486055) и MMP12 (rs2276109) с риском развития ишемического инсульта у жителей Центральной России.

\section{МАТЕРИАЛЫ И МЕТОДЫ ИССЛЕДОВАНИЯ}

Для выполнения настоящего исследования использовалась выборка неродственных индивидов жителей уроженцев Центральной России общей численностью 1073 человека, включая 666 больных ишемическим инсультом атеротромботического типа (366 мужчин и 300 женщин, средний возраст $61,7 \pm 9,8$ года) и 407 лиц контрольной группы (218 мужчин и 189 женщин, средний возраст $61,1 \pm 9,54$ года). Группы больных ИИ и контроля были русской национальности и не отличались друг от друга как по полу, так и по возрасту $(P>0,05)$. Больные ишемическим инсультом обследовались на базах неврологических отделений Курской областной клинической больницы и городской больницы скорой медицинской помощи. Детальная информация об обследованных пациентов описана нами ранее $[2,3]$. Контрольная группа формировалась из относительно здоровых добровольцев во время профессиональных осмотров, а также среди пациентов лечебнопрофилактических учреждений г. Курска и Курской области, не страдающих хроническими заболеваниями. Информированное согласие на участие в данной работе подписывалось всеми участниками исследования. Протокол исследования был одобрен Региональным этическим комитетом Курского государственного медицинского университета. Пациенты включались в группу больных при подтверждении диагноза ишемический инсульт атеротромботического типа с помощью клинических и лабораторноинструментальных методов обследования и данных компьютерной томографии головного мозга.

Геномная ДНК выделялась из венозной крови пациентов стандартным методом фенольно- хлороформной экстракции и преципитации 96\% этанолом. Генотипирование полиморфизмов rs486055 гена MMP10 и rs2276109 гена MMP12 проводилось методом полимеразной цепной реакции в режиме реального времени с дискриминацией аллелей с помощью TaqMan-зондов на амплификаторе CFX96 (BioRad, CША) в соответствии с протоколами, опубликованными в литературе $[7,23]$. Генотипирование полиморфизмов проводилось в лаборатории геномных исследований НИИ генетической и молекулярной эпидемиологии Курского государственного медицинского университета (директор, д.м.н., профессор Полоников А.В.).

Для изучения ассоциаций аллелей и генотипов полиморфных вариантов rs486055 гена $M M P 10$ и rs 2276109 гена $M M P 12$ с риском развития ИИ использовался логистический регрессионный анализ. С этой целью рассчитывались показатели отношения шансов (OR) и 95\% доверительные интервалы с коррекцией по полу и возрасту. Статистический анализ проводился с использованием статистического пакета SNPstats [28].

\section{РЕЗУЛЬТАТЫ ИССЛЕДОВАНИЯ И ИХ ОБСУЖДЕНИЕ}

Частоты генотипов исследованных полиморфизмов находились в равновесии ХардиВайнберга $(P>0,05)$. Частоты аллелей и генотипов полиморфных вариантов генов MMP10 и MMP12 в группах больных ИИ и контроля представлены в таблице 1. Как видно из таблицы 1, между группами больных ИИ и контроля установлены статистически значимые различия в частотах генотипов полиморфного варианта rs486055 гена $M M P 10(P=0,003)$. Так, гомозиготный генотип по аллелю дикого типа (T/T) ассоциировался с пониженным риском развития ишемического инсульта, независимо от пола и возраста пациентов $(\mathrm{OR}=0,4295 \%$ CI 0,22-0,80). Сравнительный анализ частот аллелей и генотипов rs2276109 MMP12 между группами не выявил статистически значимых ассоциаций указанного полиморфизма полиморфных с риском развития ишемического инсульта $(\mathrm{P}>0,05)$.

Учитывая негативное влияние курения на риск развития мозгового инсульта $[11,13]$, нам представлялось важным оценить, являются исследуемые полиморфизмы модификаторами риска развития ишемического инсульта в зависимости от наличия указанного фактора риска.

В таблице 2 представлены результаты оценки влияния курения на риск развития ИИ у носителей генотипов полиморфных вариантов генов $M M P 10$ и $M M P 12$. 
Частоты аллелей и генотипов полиморфных вариантов генов $M M P 10$ и $M M P 12$ у больных ишемическим инсультом и здоровых индивидов

\begin{tabular}{|c|c|c|c|c|c|}
\hline \multirow{2}{*}{ Ген (SNP ID) } & \multirow{2}{*}{ Генотип, аллель } & \multicolumn{2}{|c|}{ N (\%) } & \multirow{2}{*}{$P$-уровень } & \multirow{2}{*}{ OR $(95 \% \mathrm{CI})^{1}$} \\
\hline & & Здоровые & Больные ИИ & & \\
\hline \multirow{4}{*}{$\begin{array}{c}M M P 10 \\
\text { (rs486055) }\end{array}$} & $\mathrm{C} / \mathrm{C}$ & $288(70,8)$ & $456(68,5)$ & \multirow{3}{*}{0.003} & 1,00 \\
\hline & $\mathrm{C} / \mathrm{T}$ & $95(23,3)$ & $194(29,1)$ & & $1,29(0,97-1,72)$ \\
\hline & $\mathrm{T} / \mathrm{T}$ & $24(5,9)$ & $16(2,4)$ & & $0,42(0,22-0,80)$ \\
\hline & $\mathrm{T}$ & $143(17,6)$ & $226(17,0)$ & 0,72 & $0,96(0,76-1,21)$ \\
\hline \multirow{4}{*}{ MMP12 (rs2276109) } & $\mathrm{T} / \mathrm{T}$ & $304(74,7)$ & $472(70,9)$ & \multirow{3}{*}{0,40} & 1,00 \\
\hline & $\mathrm{T} / \mathrm{C}$ & $99(24,3)$ & $185(27,8)$ & & $1,19(0,90-1,59)$ \\
\hline & $\mathrm{C} / \mathrm{C}$ & $4(1)$ & $9(1,4)$ & & $1,46(0,45-4,80)$ \\
\hline & $\mathrm{C}$ & $107(13,1)$ & $203(15,2)$ & 0,18 & $1,19(0,92-1,53)$ \\
\hline
\end{tabular}

Примечание: ${ }^{1}$ - отношение шансов и 95\% доверительный интервал, скорригированные по полу и возрасту.

Таблица 2

Влияние курения на риск развития ишемического инсульта у носителей генотипов полиморфных вариантов генов MMP10 и MMP12

\begin{tabular}{|c|c|c|c|c|}
\hline Ген (SNP ID) & Генотип, аллель & $\begin{array}{c}\text { 3доровые } \\
\text { N (\%) }\end{array}$ & $\begin{array}{c}\text { Больные ИИ } \\
\text { N (\%) } \\
\end{array}$ & OR $(95 \% \mathrm{CI})^{1}$ \\
\hline \multicolumn{5}{|c|}{ Некурящие } \\
\hline \multirow{3}{*}{$\begin{array}{c}M M P 10 \\
\text { (rs486055) }\end{array}$} & $\mathrm{C} / \mathrm{C}$ & $159(70,0)$ & $159(67,9)$ & 1,00 \\
\hline & $\mathrm{C} / \mathrm{T}$ & $60(28,6)$ & $65(25,6)$ & $1,10(0,72-1,66)$ \\
\hline & $\mathrm{T} / \mathrm{T}$ & $15(1,3)$ & $3(6,4)$ & $0,20(0,06-0,69)$ \\
\hline \multirow{3}{*}{ MMP12 (rs2276109) } & $\mathrm{T} / \mathrm{T}$ & $177(75,6)$ & $158(69,3)$ & 1,00 \\
\hline & $\mathrm{T} / \mathrm{C}$ & $55(23,5)$ & $64(28,4)$ & $1,29(0,85-1,96)$ \\
\hline & $\mathrm{C} / \mathrm{C}$ & $2(0,9)$ & $5(2,2)$ & $2,85(0,54-14,95)$ \\
\hline \multicolumn{5}{|c|}{ Курящие } \\
\hline \multirow{3}{*}{$\begin{array}{c}M M P 10 \\
\text { (rs486055) }\end{array}$} & $\mathrm{T} / \mathrm{T}$ & $126(74,1)$ & $297(67,7)$ & 1,00 \\
\hline & $\mathrm{T} / \mathrm{C}$ & $35(20,6)$ & $129(29,4)$ & $1,56(1,02-2,39)$ \\
\hline & $\mathrm{C} / \mathrm{C}$ & $9(5,3)$ & $13(3,0)$ & $0,61(0,25-1,46)$ \\
\hline \multirow{3}{*}{$M M P 12(\mathrm{rs} 2276109)$} & $\mathrm{T} / \mathrm{T}$ & $125(73,5)$ & $314(41,5)$ & 1,00 \\
\hline & $\mathrm{T} / \mathrm{C}$ & $43(25,3)$ & $121(27,6)$ & $1,13(0,75-1,69)$ \\
\hline & $\mathrm{C} / \mathrm{C}$ & $2(1,2)$ & $4(0,9)$ & $0,81(0,15-4,50)$ \\
\hline
\end{tabular}

Примечание: ${ }^{1}$ - отношение шансов и 95\%-й доверительный интервал, скорригированные по полу и возрасту.

Было установлено, что протективный эффект генотипа T/T rs486055 MMP10 наблюдался исключительно у некурящих индивидов ( $\mathrm{OR}=0,20$ 95\% CI 0,06-0,69, $P=0,01)$. В то же самое время у курящих индивидов генотип Т/C rs486055 MMP10 был ассоциирован с повышенным риском развития ишемического инсульта ( $\mathrm{OR}=1,56$ 95\% CI $1,02-2,39, P=0,03)$. При этом выявленные генносредовые взаимодействия (синергизм между курением и носительством генотипов rs 486055 MMP10 в детерминации предрасположенности к ИИ) оставались статистически значимыми после коррекции по полу и возрасту методом множественной логистической регрессии.

В рамках настоящего исследования впервые в популяции русских жителей Центральной России изучены ассоциации полиморфных вариантов rs486055 гена $M M P 10$ и rs2276109 гена $M M P 12$ с риском развития ишемического инсульта. Ассоциации полиморфного варианта rs2276109 гена MMP12 с развитием ИИ не обнаружено. Вместе с тем в литературе имеются данные о потенциальной вовлеченности матриксной металлопротеиназы-12 (также известной как металлоэластаза макрофагов) в развитие и течение цереброваскулярной патологии $[10,16,17]$. Так, в тунисской популяции обнаружена ассоциация полиморфизмов с риском развития ишемического инсульта у больных сахарным диабетом [9].

Главным результатом настоящего исследования было выявление ассоциации генотипа С/T rs486055 MMP10 с повышенным риском развития ишемического инсульта исключительно у курильщиков, тогда как у некурящих индивидов 
подобная взаимосвязь генотипа с развитием болезни не обнаружена. Данная ассоциация не зависела от пола и от возраста. Это первое исследование, в рамках которого выявлена взаимосвязь полиморфизма rs486055 гена MMP10 с развитием ишемического инсульта и что выявленная взаимосвязь модулируется одним из основных факторов риска болезни - курением.

MMP10 - фермент, также известный как стромелизин-2 или транзин-2, способен деградировать различные компоненты внеклеточного матрикса, включая фибронектин, желатины I, III, IV и V типа и проколлагеназу, в меньшей степени коллагены III, IV и V типов, а также MMP1, MMP7, MMP8 и MМР9, тем самым играя роль в контроле над воспалительными процессами и целостностью сосудов [6, 22]. Примечательно, что активация экспрессии ММР10 в сосудах индуцируется провоспалительными стимулами [18], а сывороточная концентрация фермента ассоциируется с показателем толщина интима-медиа сосудов, который является маркером субклинического атеросклероза [22].

Установлено, что повышенный уровень металлопротеиназы-10 связан с повреждением головного мозга и клиническим исходом при остром ишемическом инсульте [24]. С другой стороны, известно, что ММР10 играет роль в восстановлении поражения мозга после развития ишемического инсульта, в связи с чем предлагается использовать фермент отдельно или в сочетании с тканевым активатором плазминогена для нейропротекции и тромболизиса в церебральных сосудах [20, 25, 26]. Таким образом, ММР10 представляет собой важного игрока, как в патогенезе, так и в саногенезе ишемического инсульта.

В литературе нами обнаружено только одно исследование, в котором исследовалась ассоциация полиморфных вариантов гена MMP10 с риском развития ишемического инсульта [32]. Данное исследование было выполнено в китайской популяции, в которой исследованы ассоциации двух полиморфизмов rs17435959 и rs17293607 с риском развития инфаркта мозга, однако не было выявлено взаимосвязей данных локусов с развитием болезни [32]. В другом исследовании данного коллектива авторов было установлено, что аллель С полиморфизма rs17435959 гена MMP10 ассоциируется с нестабильностью атеросклеротической бляшки в каротидных артериях, что может быть связано с развитием ишемического инсульта [31].

Полиморфизм rs486055 представляет собой нуклеотидную замену (с. $158 \mathrm{C}>\mathrm{T}$ ) во 2 экзоне гена MMP10, которая сопровождается аминокислотной заменой Arg53Lys в полипептидной цепи фермента. Анализ функционального эффекта по- лиморфизма с использованием биоинформатических инструментов SNP Function Prediction (https://snpinfo.niehs.nih.gov/snpinfo/snpfunc.html) и RegulomeDB (http://regulomedb.org) показал, данный вариант не сопровождается изменением активности ММР10, но вследствие неравновесия по сцеплению с другими полиморфизмами может быть дистанционно связан с изменением экспрессии других генов, в том числе через эпигенетическую регуляцию посредством модификации хроматина. Примечательно, что полиморфный вариант rs486055-Т ассоциируется с повышенной экспрессией гена $M M P 27$ (данные получены из базы GTEx portal, www.gtexportal.org), который гомологичен MМР10 (относится к семейству белков MMP10) и расположен в том же самом хромосомном кластере $11 \mathrm{q} 22.2$, т.е. находится в неравновесии по сцеплению с ММР10. Ген MMP27 экспрессируется практически во всех органах и тканях, но большей степени в печени, лимфоцитах, костной ткани и почках (данные получены из базы BioGPS, http://biogps.org). Хотя функции MMP27 остаются малоизученными, было установлено, что повышенный уровень экспрессии этого гена ассоциирован с развитием аневризмы аорты [14], тем самым, косвенно демонстрируя его причастность к ремоделированию сосудистой стенки посредством деградации внеклеточного матрикса. Суммируя вышеизложенное можно предположить, что фактор риска ИИ - курение, посредством активации повреждения эндотелия сосудов и индукции воспаления, а также тромбообразования (тромбин способен активировать экспрессию MMP10 [21]) способен активировать экспрессию матриксной металлопротеиназы-10. По всей видимости, в результате такой активации в церебральных артериях могут создаваться благоприятные условия для деградации внеклеточного матрикса и дестабилизации атеросклеротической бляшки, которые совместно с повышением свертывания крови провоцируют развитие атеротромботического инсульта.

Результаты настоящего исследования демонстрируют значимую роль полиморфных вариантов различных генов матриксных металлопротеиназ в формировании предрасположенности к ишемическому инсульту. Несомненно, полученные в рамках настоящего исследования результаты требуют подтверждения в независимой популяции. Дальнейшие исследования позволят пролить свет на роль данного класса генов в формировании предрасположенности к ишемическому инсульту и установить новые подходы к терапии и профилактике цереброваскулярной патологии.

Исследование выполнено при финансовой поддержке Российского научного фонда (соглашение № 15-15-10010). 


\section{ЛИТЕРАТУРА / REFERENCES}

1. Беленков Ю.Н., Мартынов А.И., Оганов Р.Г., Ольбинская Л.И., Белоусов Ю.Б., Карпов Ю.А., Кобалава Ж.Д., Лопатин Ю.М., Остроумова О.Д., Ощепкова Е.В., Скворияова В.И., Суслина З.А., Терещенко С.Н., Чазова И.Е., Шляхто Е.В. Рекомендации по вторичной профилактике инсульта (по результатам исследования PROGRESS) // АтмосферА. Кардиология. - 2003. - № 1. - C. 39-40. [Belenkov Yu.N., Martynov A.I., Oganov R.G., Ol'binskaya L.I., Belousov Yu.B., Karpov Yu.A., Kobalava Zh.D., Lopatin Yu.M., Ostroumova O.D., Oshchepkova E.V., Skvortsova V.I., Suslina Z.A., Tereshchenko S.N., Chazova I.E., Shlyakhto E.V. Recommendations for secondary prevention of stroke (based on the results of the PROGRESS study). AtmosferA. Kardiologiya. 2003; (1): 39-40 (in Russ.)].

2. Бушуева О.Ю., Стецикая Т.А., Корогодина Т.В., Иванов В.П. Полоников А.В. Влияние полиморфизма E298D гена эндотелиальной синтазы оксида азота на риск развития мозгового инсульта в зависимости от статуса курения // Генетика. - 2015. T. 51, № 2 - C. 256-262. [Bushueva O.Y., Stetskaya T.A., Korogodina T.V., Ivanov V.P., Polonikov A.V. The synergic effect of the E298D polymorphism of the endothelial nitric oxide synthase gene and smoking status on the risk of cerebral stroke. Russian Journal of Genetics. 2015; 51(2): 204-209.].

3. Вяльх Е.К., Солодилова М.А., Бушуева О.Ю., Булгакова И.В., Полоников А.В. Связь полиморфизма гена каталазы с повышенным риском развития церебрального инсульта у больных гипертонической болезнью // Журнал неврологии и психиатрии им. C.C. Корсакова. - 2012. - № 8. - C. 3-7. [Vialykh E.K., Solodilova M.A., Bushueva O.Yu., Bulgakova I.V., Polonikov A.V. Catalase gene polymorphism is associated with increased risk of cerebral stroke in hypertensive patients. Zhurnal nevrologii i psikhiatrii im. S.S. Korsakova. 2012; (8): 3-7. (in Russ.)].

4. Пигаревский П.В., Мальцеева С.В., Снегова В.А., Давыдова Н.Г., Яковлева О.Г. Ворожбит Р.А. Роль матриксной металлопротеиназы 1 типа в дестабилизации атеросклеротической бляшки у человека // Медицинский академический журнал. - 2015. T. 4. - C. 54-58. [Pigarevsky P.V., Maltseva S.V., Snegova V.A., Davydova N.G., Yakovleva O.G., Vorozhbit R.A. The role of type 1 matrix metalloproteinase in destabilization of atherosclerotic plaques in humans. Meditsinskiy akademicheskiy zhurnal. 2015; 4: 54-58 (in Russ.)].

5. Шадрина А.С., Плиева Я.3., Кушлинский Д.Н., Морозов А.А., Филипенко М.Л., Чанг В.Л., Кушлинский Н.Е. Классификация, регуляция активности, генетический полиморфизм матриксных металлопротеиназ в норме и при патологии // Альманах клинической медицины. - 2017. - Т. 45, № 4. C. 266-279. - DOI:10.18786/2072-0505-2017-45-4266-279. [Shadrina A.S., Plieva Y.Z., Kushlinskiy D.N., Morozov A.A., Filipenko M.L., Chang V.L., Kushlinskii N.E. Classification, regulation of activity, and genetic polymorphism of matrix metalloprotein- ases in health and disease. Al'manakh klinicheskoy meditsiny - Almanac of Clinical Medicine. 2017; 45(4): 266-279. (in Russ.)].

6. Bertini I., Calderone V., Fragai M., Luchinat C., Mangani S., Terni B. Crystal structure of the catalytic domain of human matrix metalloproteinase $10 / /$ J. Mol Biol. - 2004. - Vol. 336, N 3. - P. 707-716. DOI: $10.1016 /$ j.jmb.2003.12.033

7. Burger M.C. Genetic risk factors for carpal tunnel syndrome. PhD Thesis 2014, University of Cape Tow, $303 \mathrm{p}$.

8. Chang J.J., Stanfill A., Pourmotabbed T. The Role of Matrix Metalloproteinase Polymorphisms in Ischemic Stroke // Int J Mol Sci. - 2016. - Vol. 17, N 8. P. 1323. - DOI: 10.3390/ijms17081323.

9. Chehaibi K., Hrira M.Y., Nouira S., Maatouk F., Ben Hamda K., Slimane M.N. Matrix metalloproteinase-1 and matrix metalloproteinase-12 gene polymorphisms and the risk of ischemic stroke in a Tunisian population // J. Neurol. Sci. - 2014. -Vol. 342, N 1-2. P. 107-113. - DOI: 10.1016/j.jns.2014.04.036.

10. Del Porto F., Cifani N., Proietta M., Toni D., Taurino $M$. MMP-12 and TIMP Behavior in Symptomatic and Asymptomatic Critical Carotid Artery Stenosis // J Stroke Cerebrovasc Dis. - 2017. - Vol. 26, N 2. P. 334-338. $\quad-\quad$ DOI: 10.1016/j.jstrokecerebrovasdis.2016.09.025.

11. Hankey G.J. Smoking and risk of stroke // J. Cardiovasc Risk. - 1999. - Vol. 6, N 4. - P. 207-211.

12. Hassan A., Markus H.S. Genetics and ischaemic stroke // Brain. - 2000. - Vol. 123, Pt. 9. P. 1784-1812.

13. Hawkins B.T., Brown R.C., Davis T.P. Smoking and ischemic stroke: a role for nicotine? // Trends Pharmacol Sci. - 2002. -Vol. 23, N 2. - P. 78-82.

14. Lamblin N., Ratajczak P., Hot D., Dubois E., Chwastyniak M., Beseme O., Drobecq H., Lemoine Y., Koussa M., Amouyel P., Pinet F. Profile of macrophages in human abdominal aortic aneurysms: a transcriptomic, proteomic, and antibody protein array study // J. Proteome Res. - 2010. - Vol. 9, N 7. - P. 3720-3729. DOI: $10.1021 / \mathrm{pr} 100250 \mathrm{~s}$.

15. Lindgren A. Stroke genetics: a review and update // J. Stroke. - 2014. - Vol. 16, N 3. - P. 114-123. - DOI: 10.5853/jos.2014.16.3.114.

16. Ma F., Rodriguez S., Buxo X., Morancho A., RibaLlena I., Carrera A., Bustamante A., Giralt D., Montaner J., Martinez C., Bori I., Rosell A. Plasma Matrix Metalloproteinases in Patients With Stroke During Intensive Rehabilitation Therapy // Arch Phys Med Rehabil. - 2016. - Vol. 97, N 11. - 1832-1840. - DOI: 10.1016/j.apmr.2016.06.007.

17. Mahdessian H., Perisic Matic L., Lengquist M., Gertow K., Sennblad B., Baldassarre D., Veglia F., Humphries S.E., Rauramaa R., de Faire U., Smit A.J., Giral P., Kurl S., Mannarino E., Tremoli E., Hamsten A., Eriksson P., Hedin U., Mälarstig A., IMPROVE study group. Integrative studies implicate matrix metalloproteinase-12 as a culprit gene for large-artery atherosclerotic stroke // J Intern Med. - 2017. - Vol. 282, N 5. - P. 429-444. - DOI: 10.1111/joim.12655.

18. Montero I., Orbe J., Varo N., Beloqui O., Monreal J.I., Rodríguez J.A., Díez J., Libby P., Páramo J.A. 
C-reactive protein induces matrix metalloproteinase-1 and -10 in human endothelial cells: implications for clinical and subclinical atherosclerosis // J Am Coll Cardiol. - 2006. - Vol. 47, N 7. - P. 1369-1378. DOI: $10.1016 /$ j.jacc.2005.10.070.

19. Nagase H., Woessner J.F. Jr. Matrix metalloproteinases // J Biol Chem. - 1999. -Vol. 274, N 31. P. 21491-21494.

20. Orbe J., Barrenetxe J., Rodriguez J.A., Vivien D., Orset C., Parks W.C., Birkland T.P., Serrano R., Purroy A., Martinez de Lizarrondo S., AnglesCano E., Páramo J.A. Matrix metalloproteinase-10 effectively reduces infarct size in experimental stroke by enhancing fibrinolysis via a thrombin-activatable fibrinolysis inhibitor-mediated mechanism // Circulation. - 2011. -Vol. 124, N 25. - P. 2909-2919. - DOI: 10.1161/CIRCULATIONAHA.111.047100.

21. Orbe J., Rodríguez J.A., Calvayrac O., RodríguezCalvo R., Rodríguez C., Roncal C., Martínez de Lizarrondo S., Barrenetxe J., Reverter J.C., MartínezGonzález J., Páramo J.A. Matrix metalloproteinase-10 is upregulated by thrombin in endothelial cells and increased in patients with enhanced thrombin generation// Arterioscler Thromb Vasc Biol. - 2009. Vol. 29, N 12. - P. 2109-2116. - DOI: 10.1161/ATVBAHA.109.194589.

22. Orbe J., Montero I., Rodriguez J.A., Beloqui O., Roncal C., Paramo J.A. Independent association of matrix metalloproteinase-10, cardiovascular risk factors and subclinical atherosclerosis // J. Thromb Haemost. 2007. - Vol. 5. - P. 91-97. - DOI: 10.1111/j.15387836.2006.02276.x

23. Panayiotou A.G., Griffin M.B., Tyllis T., Georgiou N., Bond D., Humphries S.E., Nicolaides A.N. Association of genotypes at the matrix metalloproteinase (MMP) loci with carotid IMT and presence of carotid and femoral atherosclerotic plaques // Vasc Med. - 2013. Vol. 18, N 5. - P. 298-306. - DOI: $10.1177 / 1358863 X 13502698$.

24. Rodríguez J.A., Sobrino T., Orbe J., Purroy A., Martínez-Vila E., Castillo J., Páramo J.A. proMetalloproteinase-10 is associated with brain damage and clinical outcome in acute ischemic stroke // J. Thromb Haemost. - 2013. - Vol. 11, N 8. - P. 1464-1473. DOI: $10.1111 /$ jth. 12312 .

25. Roncal C., Martinez de Lizarrondo S., Salicio A., Chevilley A., Rodriguez J.A., Rosell A., Couraud P.O.,
Weksler B., Montaner J., Vivien D., Páramo J.A., Orbe $J$. New thrombolytic strategy providing neuroprotection in experimental ischemic stroke: MMP10 alone or in combination with tissue-type plasminogen activator // Cardiovasc Res. - 2017. - Vol. 113, N 10. - P. 1219-1229. - DOI: 10.1093/cvr/cvx069.

26. Serrano R., Purroy A., Martinez de Lizarrondo S., Angles-Cano E., Páramo J.A. Matrix metalloproteinase-10 effectively reduces infarct size in experimental stroke by enhancing fibrinolysis via a thrombinactivatable fibrinolysis inhibitor-mediated mechanism // Circulation. - 2011. - Vol. 124, N 25. P. 2909-2919. 10.1161/CIRCULATIONAHA.111.047100.

27. Sharma P., Yadav S., Meschia J.F. Genetics of ischaemic stroke // J. Neurol Neurosurg Psychiatry. 2013. - Vo. 84, N 12. - P. 1302-1308. - DOI: 10.1136/jnnp-2012-304834.

28. Solé X., Guinó E., Valls J., Iniesta R., Moreno V. SNPStats: a web tool for the analysis of association studies // Bioinformatics. - 2006. -Vol. 22, N 15. P. 1928-1929. - DOI: 10.1093/bioinformatics/btl268.

29. Stoll G., Kleinschnitz C., Nieswandt B. Molecular mechanisms of thrombus formation in ischemic stroke: novel insights and targets for treatment // Blood. - 2008. - Vol. 112, N 9. - P. 3555-3562. DOI: $10.1182 /$ blood-2008-04-144758.

30. Wen D., Du X., Nie S.P., Dong J.Z., Ma C.S. Association between matrix metalloproteinase family gene polymorphisms and ischemic stroke: a meta-analysis // Mol Neurobiol. - 2014. - Vol. 50, N 3. P. 979-985. - DOI: 10.1007/s12035-014-8687-8.

31. Zhu F., Jin X.P., Huang M.W., Zhu M., Chen Q.L., Wang F., Hu X.F., Wang W.F., Li W.L., Li C., Zhu Z.Y., Zheng Z. Association between matrix metalloproteinase-10 gene polymorphisms and instability of carotid plaque // Zhonghua Yi Xue Yi Chuan Xue Za Zhi. - 2013. - Vol. 30, N 6. - P. 711-715. - DOI: 10.3760/cma.j.issn.1003-9406.2013.06.017.

32. Zhu F., Jin X.P., Zhu M., Zhang L.L., Wang F., Wang W.F., Hu X.F., Li W.L., Li C., Zheng Z. Matrix metalloproteinase 10 gene polymorphism and atherothrombotic cerebral infarction risk in a Han Chinese population // Int J Clin Exp Med. - 2013. - Vol. 6, N 7. - P. 567-575. 